\title{
Uma Proposta de Formação Continuada
}

\section{sobre Matemática Financeira para \\ Professores de Matemática do Ensino Médio}

\author{
Raphael Pereira dos Santos \\ Universidade Severino Sombra, Mestrado Profissional \\ em Educação Matemática \\ Janaína Veiga \\ Universidade Severino Sombra, Mestrado Profissional \\ em Educação Matemática, \\ janainavcarvalho@gmail.com \\ Ilydio Pereira de Sá \\ Universidade Severino Sombra, Mestrado Profissional \\ em Educação Matemática
}

\begin{abstract}
Resumo: Este trabalho apresenta os resultados de um curso de formação continuada sobre Matemática Financeira para professores de Matemática do ensino médio realizado no município de Mangaratiba, localizado no estado do Rio de Janeiro - Brasil, e parte da hipótese de que um curso dessa natureza contribui para o desenvolvimento e a qualificação dos professores. O objetivo da formação continuada foi o de mostrar aos professores a relação dos conceitos básicos da Matemática Financeira com os conteúdos tradicionais da Matemática da escola básica. No curso ministrado, procurou-se ressaltar a importância da visualização e de softwares educativos no processo ensinoaprendizagem. Fundamentamos nossa pesquisa na perspectiva da Educação Matemática Crítica, de acordo com pesquisadores como Ole Skovsmose e Ubiratan D'Ambrosio, por acreditarmos que os conteúdos, as estratégias e a análise crítica provenientes da Matemática Financeira muito mais que descrição de algoritmos, fórmulas e cálculos descontextualizados, favorecem uma Educação Matemática que estimula a investigação e o espírito crítico do aluno/cidadão.
\end{abstract}

Palavras-chave: Matemática Financeira. Formação continuada de professores. Educação matemática crítica. Fluxo de caixa. Cidadania.

\section{A Proposition for Continuing Education on Financial}

\section{Mathematics for High-School Mathematics Teachers}

Abstract: This. This paper presents the results of a continuing education course on Financial Mathematics for High-School mathematics teachers held in Mangaratiba city, Rio de Janeiro State (Brazil), departing from the assumption that such a course contributes to the development and qualification of teachers. The purpose of continuing education was to show teachers the relationship 
between basic concepts on financial mathematics and the traditional contents from Primary School Mathematics. In the course taught, sought to emphasize the importance of visualization and educational software in teaching-learning process. We based our research on critical mathematics educational perspective, according to researchers like Ole Skovsmose and Ubiratan D'Ambrosio. Thus, we believe that, much more than describing algorithms, formulas and decontextualized calculations, financial mathematics' critical analysis of content and strategies favor the Educational Mathematics, fostering the student/citizen's research and critical spirit.

Keywords: Financial Mathematics. Continuing teacher education. Critical mathematics education. Cash flow. Citizenship.

\section{Introdução}

O presente estudo insere-se na linha de pesquisa "Metodologias e Tecnologias de Informação Aplicadas ao Ensino de Matemática", do Programa de Pós-Graduação Stricto Sensu Mestrado Profissional em Educação Matemática da Universidade Severino Sombra (USS).

$\mathrm{Na}$ graduação, quando cursava o segundo período de Licenciatura em Matemática na Universidade Federal do Rio de Janeiro (UFRJ), o primeiro autor deste trabalho teve o privilégio de participar do Projeto Fundão, um grupo de pesquisa voltado para a área de Educação Matemática, cujos encontros eram e continuam a ser realizados no Instituto de Matemática (IM) daquela instituição. Até a conclusão da graduação, participou do grupo como aluno estagiário, sendo bolsista pelo Conselho Nacional de Desenvolvimento Científico e Tecnológico (CNPq) por dois anos. Ao concluir o curso, em 2000, devido ao fato de lecionar em diferentes colégios, afastou-se dos encontros do grupo, embora sempre participasse das oficinas e congressos promovidos.

Em 2007, retornou aos encontros, participando do Grupo de Matemática Financeira orientado pela professora doutora Lilian Nasser, que o orientou, durante a graduação, em todos os congressos de que participava, como as Jornadas de Iniciação Científica da UFRJ (1996, 1997 e 1998) e o VI Encontro Nacional de Educação Matemática, realizado em São Leopoldo (RS) em 1998. Atualmente, faz parte do grupo como professor multiplicador.

Como fora apresentado à Educação Matemática ainda na graduação, já estava encantado com essa área de estudo, além de acreditar que a troca de experiências entre professores colabora para a multiplicação e trocas das ideias, ampliando o número de profissionais beneficiados.

O Grupo de Matemática Financeira do Projeto Fundão ministra oficinas em Congressos e em Semanas de Matemática em instituições de ensino superior - públicas ou particulares -, para professores que atuam em sala de aula, assim como para estudantes de licenciatura em Matemática e do ensino médio. Uma das preocupações do grupo é o despreparo dos estudantes para resolver problemas que exigem autonomia, senso crítico e tomadas de decisão. Outra questão que costuma fazer parte das discussões refere-se à inclusão da Matemática Financeira como conteúdo obrigatório na grade curricular do ensino médio. 
Com essas oficinas, objetivou-se discutir um material que aborde problemas reais do dia a dia, relacione à Matemática Financeira a outros tópicos da Matemática, valorizando o raciocínio lógico (evitando o uso de fórmulas) e adotando uma metodologia que facilitasse a compreensão, promovendo autonomia e criatividade na resolução de situações que envolvam transações comerciais e financeiras presentes no cotidiano de qualquer cidadão. A partir dessas experiências, procurou-se identificar com diversos professores quais os principais obstáculos para os alunos no processo ensino-aprendizagem de Matemática Financeira.

A maior parte dos erros na resolução de problemas ocorre devido à comparação de quantias em datas distintas (considerar que parcelas iguais em datas distintas tenham o mesmo valor); a se considerar que taxas de acréscimos ou descontos acumulados podem ser somadas em lugar de ter seus fatores de correção multiplicados; a se considerar que o valor não se altera ao longo do tempo; à utilização de juros simples em vez de juros compostos; à utilização de fórmulas sem o devido entendimento de seu significado.

Além disso, foi constatado que diversos professores, na licenciatura, não estudaram Matemática Financeira, por esta disciplina não constar da grade curricular. Em consequência, depois de formados, já atuando em sala de aula, não se sentiam preparados para abordar a temática.

Ao ingressar no Programa de Mestrado Profissional em Educação Matemática da Universidade Severino Sombra, o primeiro autor, acreditando que o ensino de Matemática Financeira deve esclarecer dúvidas, pretendia ajudar os alunos a evitar as "armadilhas" de marketing de diversas empresas quanto ao real valor dos produtos em transações comerciais e financeiras, principalmente em compras à vista e a prazo. Com a certeza de que isso poderia ser feito de modo contextualizado e dinâmico, passou a ter como objetivo o desenvolvimento de um curso de formação continuada sobre Matemática Financeira para professores de Matemática do ensino médio. $\mathrm{O}$ curso visou resgatar conteúdos de Matemática Financeira e discutir problemas pertinentes a essa temática e questões com as quais nos deparamos no dia a dia, trabalhando com a visualização com animação do fluxo de caixa da operação e com auxílio de uma ferramenta computacional como apoio ao processo ensino-aprendizagem. Tendo como orientadores a segunda autora e terceiro autor deste artigo.

Assim, foram definidos os objetivos da pesquisa:

a) Desenvolver um curso de formação continuada sobre Matemática Financeira para professores de Matemática do ensino médio.

b) Demonstrar aos professores a relação dos conceitos básicos da Matemática Financeira com os conteúdos tradicionais da Matemática.

c) Ressaltar a importância da visualização e de softwares educativos no processo ensino-aprendizagem.

Na perspectiva da Educação Matemática Crítica, de acordo com pesquisadores como Ole Skovsmose e Ubiratan D'Ambrosio, destaca-se a ideia de que a educação, necessariamente, deve ter uma dimensão de democratização. Em nossa visão, os conteúdos, estratégias e discussões da Matemática Financeira, muito mais que a descrição de algoritmos, fórmulas 
e cálculos descontextualizados são fundamentais para um ensino de Matemática que estimule a investigação e o espírito crítico do aluno/cidadão.

Acreditamos, ainda, que uma atitude crítica referente à forma como a Matemática é aplicada na sociedade deva ser construída, observando-se os fenômenos de um ponto de vista social e político. Assim, nossa proposta se alinha com as ideias da Educação Matemática Crítica.

A Matemática Financeira permite, com professores bem preparados e conscientes de sua ação política, o desenvolvimento da "matemacia" dos estudantes, entendendo, por esse termo, segundo Ole Skovsmose, uma forma de letramento matemático, provendo o suporte matemático e lógico para o exercício de uma cidadania crítica.

Ubiratan D'Ambrosio utiliza, com a mesma finalidade, o termo "materacia" que, segundo ele, é a capacidade de interpretar e manejar sinais e códigos e de propor e utilizar modelos na vida cotidiana. Trata-se de:

Promover a participação crítica de alunos/cidadãos na sociedade.

Discutir questões políticas, econômicas, ambientais, nas quais a Matemática serve como suporte.

Criticar a própria Matemática e seu uso na sociedade, indo além do processo ensinoaprendizagem.

Muitas vezes, em reuniões, seminários ou encontros de professores, quando o tema da Matemática Financeira é colocado em pauta, surgem restrições como: "ela não faz parte dos exames vestibulares"; "não é citada nos livros didáticos"; "não fomos formados para isso"; "ela não está no programa de minha escola". Mas, quem faz esses programas? Será que estamos satisfeitos com o que ensinamos? Será que gostaríamos de assistir a nossas próprias aulas?

No que se refere à apresentação do trabalho, de forma a melhor discorrer sobre o assunto da pesquisa, seus resultados e considerações estruturamos o artigo em quatro seções, além da presente Introdução, das Considerações Finais e Referências.

Na segunda seção - Educação Financeira e Cidadania -, discorreremos sobre a Educação Matemática Crítica e seus desafios, apresentando questões relevantes como educação financeira e cidadania.

Na seção 3 - Formação Continuada de Professores -, apoiamo-nos em autores que fundamentam a discussão teórica sobre a formação de professores.

Na quarta seção - Formação Continuada sobre Matemática Financeira para Professores de Matemática do Ensino Médio -, abordaremos o local em que se desenvolveu a pesquisa e a metodologia utilizada para consecução dos objetivos propostos, além de descrever os sujeitos envolvidos no processo. Também é descrita, nesta seção, uma proposta de curso de formação continuada para professores de Matemática do ensino médio.

Na seção 5 - Análise de Dados -, procederemos à análise dos dados, inicialmente com o perfil dos participantes da pesquisa delineado por meio da análise do questionário proposto, seguido da verificação do desempenho dos professores no teste diagnóstico e no pós-teste. 


\section{Educação Financeira e Cidadania}

A partir das obras de Skovsmose, durante a década de 1980, surge o movimento da Educação Matemática Crítica (EMC), que se preocupa, principalmente, com os aspectos políticos da Educação Matemática. Como uma reação ao domínio da modernização da sociedade, esse movimento tem como objetivo promover uma discussão política, democrática e tecnológica em sala de aula de Matemática. De acordo com esta proposta, o meio social, político e cultural no qual o aluno está inserido deve ter sua importância reconhecida, contando com a prática democrática no processo ensino-aprendizagem. Utilizar recursos que levem o aluno a agir e a refletir, para, de acordo com sua realidade, explorar a matemática presenciada em seu meio, muito contribuirá para uma educação matemática crítica.

A partir destes conceitos, o processo ensino-aprendizagem de Matemática passa a ser questionado, com o objetivo de se promover uma discussão política, democrática e tecnológica em sala de aula. Essa disciplina deve ser utilizada para atender à sociedade global no dia a dia, de modo a que o aluno/cidadão possa discutir os modelos matemáticos prontos e preestabelecidos para resolver situações cotidianas e, no caso de nossa proposta, que envolvem transações comerciais e financeiras.

Skovsmose (2000), criticando o caráter mecânico e repetitivo de exercícios que caracteriza o ensino tradicional de Matemática, aponta as diferenças entre o paradigma do exercício e o cenário para investigação. O primeiro, favorecendo a lógica de acerto e erro, consiste na prática de exercícios previamente estabelecidos a respeito de um determinado conteúdo matemático, enquanto o segundo é aberto ao questionamento dos alunos, ao levantamento de alternativas, tornando-os, assim, sujeitos da aprendizagem. Juntamente com o professor, os alunos são responsáveis pelo processo de ensino-aprendizagem. Para esse autor, “[...] A distinção entre o paradigma do exercício e o cenário para investigação é combinada com a diferença entre três tipos diferentes de referência: referência à matemática, referência à semirrealidade e referência à situação da vida real".

Para Skovsmose (2000, p. 67-68), "os seis possíveis ambientes de aprendizagem resultantes dessa combinação" seriam:

1 - Paradigma do exercício - referência à matemática pura: exercícios de resolução direta; por exemplo, resolução de equação.

2 - Cenário para investigação - referência à matemática pura: problemas que envolvem números e figuras geométricas; por exemplo, descobrir padrões.

3 - Paradigma do exercício - referência à semirrealidade: situações artificiais que são utilizadas para produção de exercícios.

4-Cenário para investigação - referência à semirrealidade: situações artificiais que fazem um convite aos alunos à exploração e explicação dessas situações.

5 - Paradigma do exercício - referência à realidade: situações reais por meio de problemas fechados.

6 - Cenário para investigação - referência à realidade: situações reais que serão trabalhadas em perspectiva aberta. 
Segundo Pais et al. (2003, p. 4),

Skovsmose, pensando numa educação matemática favorável para todos os alunos, referiu uma perspectiva crítica para o ensino e aprendizagem da Matemática. Essa perspectiva foi caracterizada por: a) competência crítica, com a qual os alunos poderiam participar no controle dos processos na educação; b) distância crítica, que permitiria estruturar um currículo baseado em problemas e situações verdadeiramente reais em oposição às tarefas elaboradas seguindo um domínio público construído intencionalmente, e c) engajamento crítico para um pleno envolvimento na educação. Para o autor, educação matemática nessa perspectiva crítica levaria a uma competência democrática essencial para o controle social e o exercício pleno da cidadania.

De acordo com Fonseca (2005, p. 12), "a educação matemática crítica proporciona poderes sociais, desenvolvendo uma literacia matemática ou numeracia social, permitindo aos alunos o exercício de julgamentos críticos de decisões sociais e políticas".

Na perspectiva da Educação Matemática Crítica os alunos são incentivados a se envolverem e levantarem questionamentos sobre os aspectos matemáticos presentes no cotidiano, de maneira que se "eduque" o aluno/cidadão para tomadas de decisões democráticas e conscientes em seu meio. De acordo com Passos (2007, p. 83):

Existe, portanto, uma relação entre Matemática, inovações tecnológicas e cotidiano. Essa relação pode ser mais bem compreendida a partir dos pressupostos teóricos defendidos pelas perspectivas da Educação Matemática Crítica e da Etnomatemática. A Etnomatemática, por sua vez contribui, entre outras coisas, para identificar situações cotidianas em que as ideias matemáticas se fazem presentes e como se efetiva essa presença (Passos, 2007, p. 83).

Porém, para consecução desses objetivos, é necessário o desenvolvimento de projetos matemáticos que visem à realidade, valorizando-se, também, o conhecimento matemático produzido no meio em que o aluno vive:

$\mathrm{O}$ ingrediente principal da tomada de decisão do professor quanto à direção das aulas e do aprendizado do aluno é o descobrimento, pelo professor, do conhecimento do aluno. O aluno chega ao processo educacional com uma riqueza de experiências. $\mathrm{O}$ ensino de matemática (e, aliás, da maioria das disciplinas escolares) não mais se fundamenta na estrutura da disciplina, mas ao invés, se fundamenta no conhecimento do aluno. Para tanto, o professor necessita organizar o trabalho na sala de aula de maneira a eliciar o conhecimento do aluno para que este conhecimento possa ser analisado. Também é importante criar atividades que levem o aluno a buscar em suas experiências conhecimento já formado (D’Ambrosio, 1990 apud Domite, 2002, p. 424).

A partir da década de 1970, a Etnomatemática começa a ser difundida no meio acadêmico, com base em críticas sociais em seus diferentes contextos culturais. 
O Movimento de Etnomatemática surgiu no Brasil em 1975, a partir dos trabalhos de Ubiratan D'Ambrosio:

Indivíduos e povos têm, ao longo de suas existências e ao longo da história, criado e desenvolvido técnicas de reflexão, de observação, e habilidades (artes, técnicas, techné, ticas) para explicar, entender, conhecer, aprender para saber e fazer como resposta a necessidades de sobrevivência e de transcendência (matema), em ambientes naturais, sociais e culturais (etnos) os mais diversos. Desenvolveu, simultaneamente, os instrumentos teóricos associados a essas técnicas e habilidades. Daí chamarmos o exposto acima de Programa Etnomatemática (D’Ambrosio, 2004, p. 46).

O Programa Etnomatemática proporciona elementos para que o professor de Matemática proceda a mudanças em seu planejamento e em suas ações, de modo a adaptá-los ao meio socioeconômico e cultural em que seu aluno está inserido, de forma a promover a sua autonomia, ao valorizar saberes adquiridos fora da escola:

A etnomatemática é um meio para realizar leituras do mundo, em particular do sistema escolar. Neste sentido, ela busca valorizar as relações interculturais entre as diferentes civilizações. No âmbito da educação escolar indígena, vale apontar que, ao adentrar no ambiente escolar/formador, o educador deverá levar consigo o peito aberto com a pretensão não somente de conduzir as orientações no processo de aprendizagem, mas, também, de sentir maior interesse por compreender um pouco mais o conhecimento e as individualidades emocionais das pessoas com as quais dialoga; pessoas de distintas culturas conhecendo-se mutuamente (Ribeiro e Ferreira, 2004, p. 159).

Como estratégia da ação educativa, objetivando uma nova postura educacional, D’Ambrosio (2001, p. 66-67) declara:

Proponho um currículo baseado em literacia, materacia e tecnoracia, que é uma resposta educacional à responsabilidade de proporcionar aos jovens os instrumentos necessários para sua sobrevivência e transcendência nos anos futuros, e ao mesmo tempo tornar reais as expectativas de se eliminarem iniquidades e violações da dignidade humana, como primeiro passo para a justiça social. [...] As palavras literacia, materacia e tecnoracia são pouco utilizadas. Acho adequado propor algumas definições, que ampliam o modo como esses neologismos vêm sendo utilizados, tanto em português quanto em inglês: literacia é a capacidade de processar informação escrita e falada, o que inclui leitura, escritura, cálculo, diálogo, ecálogo, mídia, internet na vida cotidiana (instrumentos comunicativos); materacia é a capacidade de interpretar e analisar sinais e códigos, de propor e utilizar modelos e simulações na vida cotidiana, de elaborar abstrações sobre representações do real (instrumentos intelectuais); tecnoracia é a capacidade de usar e combinar instrumentos, simples ou complexos, inclusive o próprio corpo, avaliando suas possibilidades e suas limitações e a sua adequação a necessidades e situações diversas (instrumentos materiais). 
Entretanto, essas mudanças não implicam que a matemática acadêmica deva ser ignorada:

\begin{abstract}
Não se trata de ignorar nem rejeitar a matemática acadêmica, simbolizada por Pitágoras. Por circunstâncias históricas, gostemos ou não, os povos que, a partir do século XVI, conquistaram e colonizaram todo o planeta, tiveram sucesso graças ao conhecimento e comportamento que se apoiava em Pitágoras e seus companheiros da bacia do Mediterrâneo. Hoje, é esse conhecimento e comportamento, incorporados na modernidade, que conduz o nosso dia a dia. Não se trata de ignorar nem rejeitar conhecimento e comportamento modernos. Mas, sim, aprimorá-los, incorporando a eles valores de humanidade, sintetizados numa ética de respeito, solidariedade e cooperação (D'Ambrosio, 2001, p. 42-43).
\end{abstract}

Uma educação de qualidade não é avaliada pela quantidade de conteúdos matemáticos ensinada pelo professor e assimilada pelo aluno. Um sistema educacional no qual o processo ensino-aprendizagem é verificado por avaliações de caráter probatório não é mais sustentável. O que de fato se espera é que a educação permita ao aluno o exercício pleno de seus direitos e deveres como cidadãos. Assim, cabe aos professores direcionar seu trabalho em sala de aula para atender e facilitar o processo de aprendizagem de seus alunos. Segundo consta nos "Parâmetros Curriculares Nacionais: Matemática" (Brasil, 1998, p. 77):

O conhecimento crítico da realidade em que desenvolve seu trabalho e dos valores que aí se encontram e que o norteiam é o ponto de partida para a organização do trabalho do professor na escola. Esse conhecimento envolve questões diretamente relacionadas ao trabalho em sala de aula e questões mais amplas, que extrapolam esse âmbito. O professor assume ao mesmo tempo duas tarefas: uma delas é conhecer melhor os seus alunos, tanto no que diz respeito estritamente ao processo ensino e aprendizagem como a desejos, interesses, dificuldades, experimentados por eles em suas vidas; a outra é a ampliação do conhecimento de si mesmo.

O que se pretende é promover, de fato, alunos/cidadãos com uma participação crítica na sociedade, capazes de analisar, entender e discutir questões sociais, econômicas e políticas.

D’Ambrosio relaciona ainda a matemática à formação de conceitos éticos, que levariam o homem a uma cultura de paz:

A matemática, como uma forma de conhecimento, tem tudo a ver com ética e, consequentemente, com a paz. A busca de novas direções para o desenvolvimento da matemática deve ser incorporada ao fazer matemático. Devidamente revitalizada, a matemática, como é hoje praticada no âmbito acadêmico e organizações de pesquisa, continuará sendo o mais importante instrumento intelectual para explicar, entender e inovar, auxiliando principalmente na solução de problemas maiores que estão afetando a humanidade. Será necessário, sem dúvida, reabrir a questão dos fundamentos, evidentemente um ponto vulnerável da matemática atual (D’Ambrosio, 2001, p. 71). 
A matemática, de maneira contextualizada, dará oportunidade para resolver problemas novos, mesmo os oriundos de outra cultura, e a etnomatemática servirá para oferecer possibilidades de explicações, entendimentos e resolução desses problemas. O educador terá como objetivo aprimorar práticas, reflexões e instrumentos de crítica, favorecendo uma formação cidadã dos alunos envolvidos no processo. A postura do professor se torna fundamental, pois precisa desenvolver metodologias para possibilitar aos alunos estratégias diferentes de resolução para problemas comuns e presentes na sociedade, em todos os níveis da Matemática, como a Matemática Financeira. Porém, é necessária uma boa formação do profissional que atua em sala de aula para desenvolver esta postura.

\section{Formação Continuada de Professores}

De maneira geral, nossa sociedade não sabe lidar com a realidade do sistema monetário vigente no país e a falta de conhecimentos matemáticos relacionados ao assunto contribui bastante para isso.

Com o aprendizado proporcionado pela Matemática Financeira, alunos do ensino médio estarão preparados para resolver situações-problema que lhes são impostas no dia a dia, identificando o que lhes seria mais favorável em transações comerciais e financeiras, seja na tomada de decisão quanto a compras à vista ou a prazo, seja com relação às taxas de juros praticadas pelo mercado, dentre outras.

É importante ressaltar que o ensino de Matemática Financeira converge para as três finalidades do ensino médio, apresentadas no Artigo 35, da Lei de Diretrizes e Bases da Educação Nacional (Brasil, 1996):

\footnotetext{
O Ensino Médio, etapa final da Educação Básica, com duração mínima de três anos, terá como finalidade:

I - a consolidação e aprofundamento dos conhecimentos adquiridos no ensino fundamental, possibilitando o prosseguimento dos estudos;

II - a preparação básica para o trabalho e a cidadania do educando como pessoa humana, incluindo a formação ética e o desenvolvimento da autonomia intelectual e do pensamento crítico;

III - a compreensão dos fundamentos científicos e tecnológicos nos processos produtivos, relacionando a teoria com a prática, no ensino de cada disciplina.
}

Observa-se que, na maioria dos cursos de licenciatura em Matemática nas faculdades do país, a disciplina Matemática Financeira não consta como obrigatória em sua grade curricular - em muitas, nem como disciplina optativa. Em consequência, esses professores concluem a licenciatura totalmente despreparados para lecionar o referido conteúdo, o que implica exploração pouco satisfatória do tema em sala de aula. Entretanto, o professor precisa desenvolver metodologias para incentivar os alunos no ensino da Matemática e desafiá-los para a resolução de problemas diários que envolvam tomadas de decisões.

Mas... Como o professor desempenhará esse papel na sociedade e promoverá a conexão do aluno às situações reais e desafiadoras do dia a dia, se não tem, em sua formação, bagagem suficiente para corresponder à expectativa? 
Para que o professor se mantenha atualizado, enriquecendo sua prática pedagógica e beneficiando a aprendizagem do aluno, contribuindo para uma formação cidadã, ou para aqueles que tentam minimizar as lacunas da formação inicial, os cursos de formação continuada se constituem em ferramentas indispensáveis na ampliação de conhecimentos e inovação de suas práticas de ensino.

De acordo com os "Parâmetros Curriculares Nacionais: Matemática" (Brasil, 1998, p. 79):

\begin{abstract}
Um projeto pedagógico que inclua o trabalho com os temas transversais exige dos professores um redimensionamento de sua ação, uma vez que este trabalho envolverá, além do conteúdo específico de sua área, a preocupação em trabalhar valores. Todas as áreas do conhecimento e temas transversais têm contribuições a oferecer no sentido de incentivar valores fundamentais para a formação do cidadão.
\end{abstract}

A tarefa do professor, assim, extrapola os limites da sala de aula, à medida que precisa, de fato, renovar a concepção tradicional da matemática escolar: aula expositiva; soluções mecânicas, com uso de fórmulas; professor como único responsável pelo processo ensinoaprendizagem etc. Pelo contrário: é necessário criar situações que despertem a criatividade do aluno, que o motivem a investigar as situações a ele apresentadas.

Paulo Freire, para quem o educando é o sujeito do processo educativo, tem seu fundamento teórico baseado na convicção de que "em toda relação entre educador e educando está sempre em jogo algo que se procura conhecer" (Freire, 1992, p. 25).

\footnotetext{
A proposta de Freire em fazer o/a professor/a voltar-se para seus alunos e alunas é fundamentalmente diferente de todas as posições pedagógicas e epistemológicas precedentes. Tal afirmação se justifica pelo menos por duas atitudes/posições do autor: primeiro, segundo Freire, o papel do/a professor/a no grupo não é de quem procura interagir com o/a aluno/a discutindo relações sobre conteúdos específicos e muito menos não é o de quem transmite conhecimento, mas o de quem por meio do diálogo procura conhecer com os/ as alunos/as - ao ensinar algo aos alfabetizandos o professor aprende deles algo também (Freire, 1980 apud Domite, 2002, p. 426).
}

Esse educador acreditava ser a educação um fenômeno social capaz de mudar a realidade de um país. Ele desenvolveu seu método de alfabetização pautando-se no potencial humano para a criatividade e a liberdade no interior de estruturas políticas, econômicas e culturais opressoras.

Um dos aspectos que se ressaltam em seu método de alfabetização é fazer com que o professor desenvolva, no processo ensino-aprendizagem, questões que retratem a realidade do povo.

Seguindo a filosofia de Paulo Freire, a matemática escolar deve ser trabalhada de maneira que possibilite ao aluno participar e interagir na sociedade da qual faz parte, assim como o professor precisa ser um mediador e respeitar em sua prática pedagógica a autonomia de ser e de saber do educando, aproveitando o conhecimento que o educando traz para a escola. 
De acordo com Freire (1996, p. 25), "Não há docência sem discência, as duas se explicam, e seus sujeitos, apesar das diferenças que os conotam, não se reduzem à condição de objeto, um do outro. Quem ensina aprende ao ensinar, e quem aprende ensina ao aprender". Ou seja, o professor não é superior nem mais inteligente que o aluno e, sim, participante do mesmo processo de construção do conhecimento.

Outro aspecto importante da obra de Freire é que os professores têm grande responsabilidade ao ensinar e, por isso, devem ser dotados de ética, combatendo a ética do mercado mundial baseada em lucros, discutindo preconceitos no processo educativo. A educação não pode ser imobilizadora e ocultadora de verdades como as classes dominantes enxergavam.

De acordo com os "Parâmetros Curriculares Nacionais: Ensino Médio" (Brasil, 1999, p. 79):

\footnotetext{
No campo da ética guarda-se a proposta de uma educação em valores. Valores de diversas ordens estão presentes na vida escolar, em todos os seus aspectos - ao promover a aprendizagem nas diversas áreas, os professores estão, de alguma maneira, procurando despertar nos alunos o respeito por inúmeros valores humanos, como a exatidão, a precisão, a curiosidade, a verdade. Com esses valores articulam-se os valores morais, objetos da reflexão ética. Assim, a ética atravessa a proposta educacional da escola e o planejamento e execução do trabalho de cada um dos professores e da relação de todos os que compõem a comunidade escolar.
}

O estudar, de fato, envolve questões de valores, ou seja, não há um conhecimento totalmente neutro. Além disso, é exercício da cidadania. É por meio de seus saberes que o indivíduo participará do mundo de trabalho, da vida cotidiana e contribuirá para o bemestar próprio e de todos.

Entretanto, para que os professores estejam aptos a desempenhar a postura considerada ideal por Freire, precisam, principalmente, ter formação sólida de conceitos morais e intelectuais, para encontrar alternativas que facilitem a aprendizagem e a troca de conhecimentos com os alunos.

Para tanto, os cursos de capacitação e formação continuada são importantes, pois objetivam complementar a formação teórica recebida na graduação, às vezes, já defasada. Por meio da atualização de práticas didático-metodológicas, eles proporcionam, aos professores, alternativas para expor determinados assuntos, com atividades que desenvolvam a capacidade crítica, a auto-reflexão e a autonomia de seus alunos.

O pressuposto básico que orienta esses cursos é o de que o professor não é objeto do planejamento do trabalho, mas agente ativo desse processo. Nessa perspectiva, buscase resgatar, no professor, o papel de sujeito do processo do conhecimento. Na etapa de planejamento, precisam ser discutidos e definidos os objetivos do trabalho, as estratégias de ensino, as reformulações das atividades propostas, o planejamento e replanejamento das aulas, os critérios e os instrumentos de avaliação etc. 


\section{Formação Continuada sobre Matemática Financeira para Professores de Matemática do Ensino Médio}

Nosso objetivo nesta pesquisa foi desenvolver um curso de formação continuada sobre Matemática Financeira para professores de Matemática do ensino médio.

Nesta seção, descreveremos a proposta do curso aplicado aos professores de Matemática do ensino médio que atuam na Prefeitura Municipal de Mangaratiba, no estado do Rio de Janeiro.

\section{Local da Pesquisa}

Mangaratiba é um município do estado do Rio de Janeiro. De acordo com a contagem da população de 2009, realizada pelo Instituto Brasileiro de Geografia e Estatística (IBGE), a cidade possui 32.533 habitantes. O território municipal estende-se por $360,71 \mathrm{~km}^{2}$, contando com mais de 34 praias ao longo de sua faixa litorânea, o que faz com que a cidade seja bastante frequentada por turistas.

A rede municipal de educação dispõe de 35 escolas, distribuídas em seis distritos, oferecendo educação infantil, ensino fundamental do primeiro ao nono ano e ensino fundamental noturno acelerado. Há duas escolas que oferecem o ensino médio.

Em Mangaratiba, a educação é incentivada e os professores têm constantemente oferta de cursos, palestras e encontros promovidos pela Secretaria de Educação.

Há alguns anos, a prefeitura tem recebido alguns prêmios, como:

Educação de Ouro: concedido pelo Instituto Nacional de Estudos e Pesquisas Educacionais Anísio Teixeira (INEP) aos municípios que mais se destacaram no ano de 2005 no envio de projetos ao Ministério da Educação/Fundo Nacional de. Desenvolvimento da Educação (MEC/FNDE) e na qualificação de seus professores, promovendo, assim, uma melhoria efetiva do ensino.

Palma de Ouro 2006, 2007 e 2008: premiação, em âmbito nacional, às secretarias municipais que se diferenciam na elaboração de projetos, no gerenciamento e na aplicação dos recursos públicos na educação.

Cultura Nota 10: uma iniciativa da Secretaria de Cultura do Estado do Rio de Janeiro, apoiada pela Organização das Nações Unidas para a Educação, a Ciência e a Cultura (UNESCO). Trata-se da maior premiação destinada a projetos culturais no Rio de Janeiro e tem como objetivo incentivar iniciativas de baixo custo que valorizem a identidade do município ou da região, entre outros.

Mangaratiba tem, ainda, o Programa Escola Aberta: integração Escola x Comunidade, criada a partir de um acordo de cooperação técnica entre o Ministério da Educação e a UNESCO. Seu objetivo é contribuir para a melhoria da qualidade da educação, a inclusão social e a construção de uma cultura de paz, por meio da ampliação das relações entre escola e comunidade e do aumento das oportunidades. Com isso, proporciona aos alunos 
da educação básica das escolas públicas e às suas comunidades espaços alternativos, nos finais de semana, para o desenvolvimento de atividades de cultura, esporte, lazer, geração de renda, formação para a cidadania e ações educativas complementares.

Todas as escolas do município são equipadas com uma sala de informática, na qual os professores desenvolvem, com os alunos, temas diversos das disciplinas que lecionam.

O município possui também um Centro Educacional de Interatividade Digital (CEID), projeto de inclusão digital que visa a possibilitar a alunos da rede municipal, bem como a outras pessoas da comunidade, acesso à Internet e conexão com museus virtuais e programas educacionais de ciências.

Alguns dos recursos oferecidos nesse centro são: computadores conectados à internet para aulas de pesquisa em sítios educacionais, quiosque TryScience (museu virtual de Ciências do mundo, que disponibiliza para crianças, jovens e adultos exposições interativas e aventuras multimídia, além de atividades científicas práticas que podem ser executadas em casa ou na escola), quiosque eternal Egypt (museu virtual que permite aos alunos se mover livremente pelos ambientes virtuais, onde artefatos e locais individuais podem ser explorados e apreciados), quiosques KidSmart (computadores equipados com programas educacionais que abordam temas de diferentes áreas do conhecimento, como Ciências, Matemática, Geografia, dentre outros, voltados para crianças de três a sete anos).

Há também um auditório bem sonorizado, com capacidade para 35 pessoas e equipado com projetor multimídia e quadro digital. Este foi o local escolhido para abrigar a primeira sessão do curso de formação continuada, onde foi discutida a proposta e apresentados os sujeitos da pesquisa, além da aplicação do questionário e do teste diagnóstico.

A partir da segunda sessão, o curso passou a ser realizado na Escola Municipal Coronel Moreira da Silva, situada no centro de Mangaratiba, localizado no 1. ${ }^{\circ}$ Distrito. A escola, segundo sua diretora, Glória Maria, tem alguns programas do MEC, como: Programa Escola Aberta: Integração Escola x Comunidade; Programa Mais Educação, com aulas de reforço escolar em contraturno, de segunda a sexta-feira; Plano de Desenvolvimento da Educação (PDE), em que a verba destinada ao apoio pedagógico é aplicada na construção de laboratórios, realização de palestras para professores; contratação de ônibus para locomoção de alunos em eventos etc.

A exemplo das outras escolas do município, esta dispõe de um laboratório de informática do Programa Nacional de Tecnologia Educacional (PROINFO), onde foram desenvolvidas as demais sessões do curso de formação continuada.

\section{Abordagem Metodológica}

Segundo Minayo (1994, p. 16), a metodologia

[...] inclui as concepções teóricas de abordagem, o conjunto de técnicas que possibilitam a construção da realidade e o sopro divino do potencial criativo do investigador. Enquanto abrangência de concepções teóricas de abordagem, a teoria e a metodologia caminham juntas, intrincavelmente inseparáveis. Enquanto conjunto de técnicas, a metodologia deve dispor de um instrumental claro, coerente, elaborado, capaz de encaminhar os impasses teóricos para o desafio da prática. 
As metodologias alternativas (não convencionais) aparecem, nesses últimos 30 anos, como maneiras de se buscar novos caminhos diante de uma realidade cada vez mais dinâmica. Adotam ideias contrárias às da metodologia científica, que estabelecem o primado do método sobre a realidade. A compreensão do papel fundamental, na pesquisa, dos sujeitos pesquisados é a característica básica das metodologias alternativas.

Um de seus principais objetivos consiste em fornecer a pesquisadores e grupos de participantes meios para se tornarem capazes de responder com maior eficiência a situações-problema, para o que os procedimentos convencionais têm pouco contribuído.

Thiollent (2000) afirma que não despreza a pesquisa teórica, considerando-a de fundamental importância, mas a sua opção é pela pesquisa empírica, com observação e ação em meios sociais delimitados. Apesar de sua escolha, sua abordagem não desconsidera questões relativas aos quadros de referência teórica, sem os quais a pesquisa empírica não faria sentido:

\footnotetext{
Os temas e problemas metodológicos aqui apresentados são limitados ao contexto da pesquisa com base empírica, isto é, da pesquisa voltada para a descrição de situações concretas e para a intervenção ou ação orientada em função da resolução de problemas efetivamente detectados nas coletividades consideradas (Thiollent, 2000, p. 9)
}

Essa questão, frequentemente abordada por autores do tema, é a diferença entre a pesquisa não convencional e a convencional. Nessa última, não há participação dos pesquisadores junto às pessoas da situação observada, assim como entre os seus resultados há uma distância significativa. Em contrapartida, na primeira é possível estudar dinamicamente problemas, decisões, ações, negociações, conflitos e tomadas de consciência que ocorrem entre os agentes durante o processo de transformação da situação (Thiollent, 2000).

A abordagem metodológica desta pesquisa consiste, em parte, de alguns dos principais aspectos da pesquisa-ação, que é uma estratégia metodológica da pesquisa social na qual, segundo Thiollent (2000, p. 16):
a) há uma ampla e explícita interação entre pesquisadores e pessoas implicadas na situação investigada;
b) desta interação resulta a ordem de prioridade dos problemas a serem pesquisados e das soluções a serem encaminhadas sob forma de ação concreta;
c) o objeto de investigação não é constituído pelas pessoas e sim pela situação social e pelos problemas de diferentes naturezas encontradas nesta situação;
d) o objetivo da pesquisa-ação consiste em resolver ou, pelo menos, em esclarecer os problemas da situação observada.

Como parte da metodologia, foi aplicado um questionário aos professores, o qual deveria ser respondido por escrito e sem a presença do entrevistador. De modo a definir o perfil dos professores participantes da pesquisa, são apresentadas 34 perguntas referentes a dados pessoais, formação acadêmica, atuação profissional, motivações para lecionar, opinião sobre a Matemática Financeira e cursos de formação continuada. 
Juntamente com o questionário, foi fornecido o Termo de Consentimento Livre e Esclarecido, do Comitê de Ética em Pesquisa da Universidade Severino Sombra, explicando a natureza da pesquisa, seus objetivos e procedimentos, assim como coletando autorização para utilização de imagens dos participantes e garantindo o anonimato.

Com relação à aplicabilidade do questionário, como toda técnica de coleta de dados, apresenta vantagens e desvantagens. Como vantagens, Marconi e Lakatos (2007, p. 204) enumeram:

Economiza tempo, viagens e obtém um grande número de dados; atinge maior número de pessoas simultaneamente; obtém respostas mais rápidas e mais precisas; há maior liberdade nas respostas em razão do anonimato; há mais segurança, pelo fato de as respostas não serem identificadas; há menos risco de distorção, pela não influência do pesquisador.

Ainda, segundo Marconi e Lakatos (2007), o questionário deverá apresentar três importantes elementos: fidedignidade (qualquer pessoa que o aplique obterá sempre os mesmos resultados); validade (os dados recolhidos são necessários à pesquisa) e operatividade (o vocabulário é acessível e de significado claro).

\section{Sujeitos da Pesquisa}

Os sujeitos da pesquisa são professores da rede municipal de ensino de Mangaratiba, que também trabalham no ensino médio. Do curso de formação continuada, participaram 20 professores.

Um dos objetivos desta pesquisa era confirmar uma de nossas hipóteses, qual seja a de que um curso de formação continuada oferece subsídios teórico-metodológicos para o professor, propicia o uso e a familiarização com as tecnologias educacionais, ajuda na construção de propostas de ação interdisciplinares, além de motivar reflexões sobre a prática diária.

Como muitos professores não estudaram, na graduação, os conteúdos de Matemática Financeira, sentem dificuldade em lecioná-los de maneira contextualizada no ensino médio, a não ser por aplicação de fórmulas, seguindo o modelo difundido na maioria dos livros didáticos para o ensino médio.

Assim, acreditamos que um curso dessa natureza ajudará esses profissionais a lidar com esse assunto com uma abordagem contextualizada, de modo a facilitar a compreensão e promover a autonomia e a criatividade de seus alunos na resolução de problemas e situações a eles apresentados.

Além do curso, o uso de uma ferramenta computacional, com um software específico, facilitará o ensino da Matemática Financeira, contribuindo para melhoria do processo ensino-aprendizagem da Matemática de forma geral. 


\section{Desenvolvimento do Curso de Formação Continuada}

Inicialmente, foi discutido com o diretor de ensino de Mangaratiba que o curso de formação continuada seria destinado a professores que atuassem em toda a rede de ensino daquele município. Entretanto, devido ao grande número de escolas e de professores, acordamos que o curso abrigaria 20 professores, todos da rede municipal de Mangaratiba, com prioridade para aqueles que também trabalhassem em alguma escola de ensino médio (pública ou particular).

Realizado no período de 22 a 27 de novembro de 2010, o curso teve a presença de 20 professores, todos atuando no ensino fundamental e médio. O que mais chamou a atenção foi o interesse desses profissionais na aquisição de novos conhecimentos para levar para sala de aula.

O curso de formação continuada teve uma carga horária de 30 horas, distribuídas em 10 sessões de três horas cada, de segunda a sexta-feira, nos horários de $9 \mathrm{~h}$ as $12 \mathrm{~h}$ e de 14 $\mathrm{h}$ as $17 \mathrm{~h}$, à exceção dos dias 26 e 27, quando foi realizado apenas na parte da manhã. $\mathrm{O}$ cronograma apresentado aos professores no primeiro dia de curso foi seguido conforme o programado.

Na primeira sessão, promovemos um debate sobre Matemática Financeira, sua importância e implicações no cotidiano, a proposta para o curso, o uso do computador em sala de aula e a validade de cursos de formação continuada. Houve, também, distribuição dos questionários e a aplicação do teste diagnóstico.

Na segunda sessão, discutimos aspectos da inflação, deflação e desinflação relacionados ao cotidiano, incentivando os professores a citarem exemplos. Também foram discutidas taxas nominais e reais.

Nas terceira e quarta sessões, o assunto foi valor do dinheiro no tempo; trabalhamos com problemas extraídos de jornais e revistas, exemplos de compras à vista e a prazo. O que mais nos despertou a atenção foi o fato de muitos professores considerarem que quantias em datas diferentes tinham o mesmo valor; quando, com a animação no computador, eles visualizaram as parcelas indo para uma única data no fluxo de caixa, percebia-se admiração e empolgação por parte dos professores. Muitos afirmaram que se tratava de uma metodologia nova para eles no ensino de Matemática Financeira e que, para os alunos, o processo seria de rápida aceitação e entendimento.

$\mathrm{Na}$ quinta sessão, os assuntos abordados foram juros simples e progressões aritméticas. O objetivo era relacionar a Matemática Financeira a outros tópicos da Matemática e estabelecer suas relações com situações do cotidiano como, por exemplo, juros de mora.

Na sexta e sétima sessão tratou-se de juros compostos e progressões geométricas. Também com o auxílio do computador, foram feitas animações para os exercícios de juros compostos, os quais foram relacionados a progressões geométricas e a outros tópicos da Matemática. As relações que iam sendo construídas eram discutidas para entendimento dos conceitos envolvidos, assim como ressaltada a importância de estabelecer tais procedimentos em sala de aula, para que os alunos não só resolvessem problemas com o uso de fórmulas, como também entendessem o que estivesse acontecendo naquele processo. 
$\mathrm{Na}$ oitava sessão, o assunto foi capitalização. Promovemos discussões com problemas extraídos de jornais e revistas trazidos pelos professores. Este era um assunto ao qual os professores atribuíam dificuldade antes do curso, porém, com as discussões levadas a efeito nas sessões anteriores, passamos a considerá-lo esclarecido. A partir dessa sessão, os professores já resolviam os problemas propostos com facilidade.

Na nona sessão, trabalhamos amortização. Da mesma forma que na capitalização, os professores já se sentiam à vontade para resolver os problemas. Como havia opções de raciocínios diferentes para se chegar à resposta, cada professor optava por resolver da maneira que lhe parecesse mais fácil. Depois, discutíamos como cada um alcançara aquele resultado, de modo a que todos assimilassem as diversas formas de resolver a questão.

Na décima sessão, além de aplicação do teste pós-curso, foram discutidos os tópicos abordados no decorrer do curso. Os professores demonstraram grande satisfação por terem participado do curso. Foi informado a eles que, caso o desejassem, poderiam deixar um depoimento sobre o curso.

\section{Análise dos Dados}

De posse dos questionários, da avaliação diagnóstica, do teste diagnóstico e do teste póscursos procedemos à sondagem do nível de conhecimento dos professores sobre Matemática Financeira, assim como à identificação do perfil de cada professor participante.

\section{Perfil dos Participantes da Pesquisa}

A partir da análise do questionário aplicado, delineamos o perfil dos participantes do curso de formação continuada.

Do total de 20 professores, no que se refere a gênero, são 12 homens e oito mulheres. Com relação ao estado civil e situação familiar, $80 \%$ são casados e $20 \%$ têm filhos. No quesito idade, faixa etária entre 26 e 40 anos. Dois professores nasceram em Mangaratiba e dez, lá residem, atualmente, em função de lecionarem na cidade. Dos professores que não moram no município, apenas três moram em cidades distantes, sendo os únicos a utilizar ônibus como meio de transporte para o trabalho, gastando, diariamente, mais de duas horas nesse deslocamento. Para evitar desgaste, esses professores não retornam à sua cidade no mesmo dia, e pernoitam no município para lecionar no dia seguinte, quando retornam para suas casas.

Em relação à escolarização, $60 \%$ dos professores participantes cursaram o ensino básico em escola particular, enquanto $40 \%$ em pública. $80 \%$ tiveram uma escolarização regular. $10 \%$ supletiva e $10 \%$ parcialmente supletiva.

Quanto à graduação, apenas 25\% estudaram em instituição pública; os demais, em particulares. A maioria dos professores concluiu a graduação há poucos anos; entretanto, há um professor que conta 18 anos de formado. Apenas 15\% tentaram outra graduação, mas nenhum a completou.

Em relação a cursos de pós-graduação, $65 \%$ dos professores haviam concluído uma pós-graduação lato sensu; destes, $15 \%$ a cursaram em instituição pública. Os demais professores $(35 \%)$ afirmaram que gostariam de cursar uma pós-graduação, sendo que 
as principais razões que até aquele momento os impediam eram: sobrecarga de trabalho profissional, questões financeiras e distância entre as instituições de ensino e o local de moradia.

Em relação à atuação profissional, todos os professores atuam nos ensinos fundamental e médio e lecionam a disciplina de Matemática, sendo que 20\% deles lecionam, também, a disciplina de Física. Dos professores, 70\% já lecionaram em mais de cinco escolas simultaneamente; hoje, $40 \%$ atuam em três ou mais escolas.

Em relação aos aspectos negativos de sua atuação na escola, foram citados: cansaço, provocado pelo deslocamento entre uma escola e outra (que muitas vezes reflete em sala de aula) e baixos salários do magistério em geral. Como aspectos positivos, foram apontados: o incentivo que a prefeitura dá aos projetos; os cursos de formação continuada; a boa relação com os alunos; o incentivo a salas de informática e multimídia para uso dos alunos; aulas com softwares matemáticos; preparação de materiais nos laboratórios (que são bem estruturados); organização nos conteúdos e atividades propostas com auxílio da direção e Secretaria de Educação; boa relação com os outros professores e com o quadro de funcionários da escola.

No que concerne às motivações que os levaram a ser professores e o fator determinante para a escolha, 70\% responderam: a facilidade para a disciplina de Matemática na escola básica e o gosto por esta disciplina; o período noturno em que o curso de licenciatura em Matemática era oferecido; o preço da mensalidade, que cabia no orçamento na época em que cursavam a graduação; a distância entre a faculdade e o trabalho/local de moradia; o fato de ser, na época, um dos poucos cursos de graduação ofertados na região.

Com relação à função social do professor, todos apontaram a sua responsabilidade em formar adolescentes e adultos - cidadãos - com cultura, voltados para o bem e longe das drogas e da criminalidade; preocupação com o futuro das crianças e do país e em dar oportunidade às crianças para que tenham um futuro melhor por meio do estudo.

Quanto ao nível de satisfação profissional, 70\% classificam como bom. A maioria afirma gostar de lecionar e que o fazem por prazer e satisfação. Em contrapartida, o baixo salário é apontado como único agente de desmotivação.

Quanto à disciplina de Matemática Financeira, 40\% afirmaram que a estudaram na graduação. Todos os professores são de opinião de que essa disciplina deve ser obrigatória no currículo do ensino médio, destacando sua importância na formação do aluno. Alegaram, ainda, que estavam no curso para aprender novas formas de lecionar tal conteúdo, pois os livros didáticos que utilizam só ensinam a aplicação de fórmulas.

No que se refere à oportunidade de participar de um curso de formação continuada na área de Matemática, a maioria (75\%) respondeu que já havia feito um curso de formação continuada e que isso se devia à prefeitura de Mangaratiba. Dez por cento dos professores não haviam tido oportunidade, enquanto $15 \%$ iniciaram um curso de formação continuada, mas, por motivos particulares, não o concluíram.

Todos opinaram positivamente a respeito de um curso de formação continuada, alegando que um curso dessa natureza permite aos professores reflexões sobre uma visão atualizada de promover a educação. Relembrar certos conteúdos, aprender conteúdos que não estudaram, além de novas técnicas de ensinar foram as mais citadas pelos professores. 
Uma Proposta de Formação Continuada sobre Matemática Financeira para Professores de Matemática do Ensino Médio

Raphael Pereira dos Santos - Janaína Veiga - Ilydio Pereira de Sá

\begin{tabular}{|c|} 
QUESTÕESDO TESTE DIAGNÓSTICO \\
\hline UNIVERSIDADE SEVERINO SOMBRA \\
PROGRAMA DE MIESTRADO PROFISSIONAL EM EDUCAÇÃo MATEMÁTICA \\
Mestrando: Raphael Pereira dos Santos \\
Orientadora: Prof Dr' Janaína Veiga Carvalho \\
Ceorientador: Prof Doutorando Ilydio Pereira de Sá \\
\hline
\end{tabular}

\section{Questão 1:}

Bruna contraiv um empréstimo de RS 300,00, a juros mensais de 15\%. Dois meses depois, pagou RS 150,00 e, um mâs após, liquidou o débito. Qual o valor desse último pagamento?

\section{Questão 2:}

Uma loja oferece uma mercadoria, à vista, por RS 400,00 , ou em duas parcelas iguais de RS 220,00 (para 30 e 60 dias). Qual tara da juros sobre o saldo devador está sendo cobrada pela foja?

\section{Questão 3:}

Qual o tempo necessário para dobrar um capital, aplicado à taxa de $1 \%$ ao mès?

\section{Questão 4:}

O presito de certo muricipio antecipa dois aumentos sucessivos aos funcionários públicos municipais: um de $5 \%$ e outro de $6,5 \%$. Na data-base, foi anunciado um reajuste da $25 \%$, descontadas as antecipacōess. Qual o reajuste percentual de avmento que esses funcionirios terio?

\section{Questão 5:}

Visando a trocar de carro as final do ano, Alberto passa a depositr, mensalmente, de agosto a dezembro, a quantia de RS 1000,00 . De quanto irá dispor em dezembro, após o úttimo depósito, se 0 banco no qual investiv ses dinheiro aplica uma taxa de juros de 29 a.m?

\section{Questẫo 6:}

Augusto comprou um televiser com pagamentos programados para 30,60 e 90 dias. 0 valor de cada parcela é de RS 500,00 e a loja, para esse tipo de financiamento, aplica juro composto correspondente a $15 \%$ a.m. Se Augusto juntasse o dinheiro para pagar à vista, qual seria o preço dasse televisor?

Figura 1. Questões do teste diagnóstico 
Uma Proposta de Formação Continuada sobre Matemática Financeira para Professores de Matemática do Ensino Médio

Raphael Pereira dos Santos - Janaína Veiga - Ilydio Pereira de Sá

\section{QUESTÕES DO TESTE PÓS-CURSO}

\section{UNIVERSIDADE SEVERINO SOMRRA \\ PROGRAMA DE MESTRADO PROFISSIONAL EMEDUCACุÃOMATEMÁTICA \\ Mestrando: Raphael Per eira dos Santos \\ Orientado ra: Prof $\mathrm{D} r$ Janaina Veiga Carvalho \\ Ceorientader: Prof Doutorando Ilydio Pereira de Sä}

\section{Questão 1:}

Viricius tomou um empréstimo de RS 5000,00, a juros mensais de 5\%. Dois meses depois, ele pagou RS 2500,00 e, um mês após esse pagamento, liquidou seu débito. Qual o valor desse Útimo pagamento?

Questão 2:

Uma loja vende um Sogão, à vista, por RS 800,00 , ou a prazo, em seis parcelas mensais e iguais de RS 180,00 , sem entrada. Qual a taxa de juros implicita na compra a prazo?

Questão 3:

Qual o tempo necessário para dobrar um capital, aplicado à taxa de $5 \%$ as mês?

\section{Questão 4:}

Em uma reuniäo de condominio, Soi aprovado um acréscimo de 10\%, em duas parcelas, sendo $5 \%$ de imediato e o restante seis meses depois. Qual deve ser a taxa de aumento da segunda parcela?

Questão 5:

Ciatina fe oito depósitos mensais de RS 500,00 em uma aplicaçio financeira, que rende 2,5\% ao mîs. Calcule o saldo acumulado na data do último depóaito.

\section{Questão 6:}

Joảo deve seis prestaç̄es mensais e iguais de RS 650,00, vencendo a primeira em 30 dias. Qual o valor atual da divida, considerando a taxa de juros de $6 \% 6$ ao mès?

Figura 2. Questões do teste pós-curso

\section{Verificação do Desempenho dos Professores}

A verificação de desempenho dos professores consistiu na análise de cada resposta dada às questões propostas, comparando-se os resultados do teste diagnóstico (Figura 1) com os do teste pós-curso (Figura 2). 
Logo na Questão 1, percebemos o grau de dificuldade dos professores. Apenas $20 \%$ dos professores acertaram a questão, enquanto $65 \%$ a erraram completamente. Já no teste pós-curso, a situação se inverteu: a maior parte dos professores acertou a questão e apenas $15 \%$ a erraram completamente.

Na Questão 2, exatamente a metade dos professores acertou a resposta, enquanto a outra metade errou completamente. Notamos que a maioria dos erros consistiu no uso incorreto de fórmulas. Já no teste pós-curso, $25 \%$ erraram completamente a questão. Dessa vez, o uso incorreto de fórmulas reduziu bastante.

Na Questão 3, apenas 25\% dos professores acertaram a questão, o que equivale a $75 \%$ de respostas incorretas. Destas, $40 \%$ consistiram em respostas em branco. Em contrapartida, no pós-teste, tivemos apenas $20 \%$ de respostas erradas, sendo $10 \%$ para respostas em branco. Constatamos que houve uma melhora significativa em relação ao teste diagnóstico nessa questão.

Na Questão 4, houve 60\% de respostas certas e 40\% de respostas completamente erradas. No pós-teste, esse percentual reduziu para $10 \%$ de respostas erradas. Esta foi a questão do teste diagnóstico que teve maior número de acertos.

Na Questão 5, tivemos os seguintes resultados no teste diagnóstico: 20\% acertaram completamente a questão, enquanto $20 \%$ a acertaram parcialmente; $60 \%$ dos professores erraram a questão, sendo que $20 \%$ a deixaram em branco. No teste pós-curso $80 \%$ acertaram completa ou parcialmente a questão e obtivemos $20 \%$ de respostas incorretas. Nessa aplicação, não houve respostas em branco.

Na Questão 6, no teste diagnóstico, o resultado foi de $15 \%$ de respostas corretas e $25 \%$ para respostas parcialmente corretas. Do total de respostas erradas, novamente tivemos respostas sem solução, que corresponderam a 10\%. No teste pós-curso, não houve respostas em branco, apresentando $45 \%$ de respostas corretas e 35\% de respostas parcialmente corretas. As respostas erradas caíram para $20 \%$ do total de professores.

Constatamos que houve, em todas as questões, uma melhora significativa. O fato é ainda mais relevante se levarmos em conta que muitos professores não tinham clareza sobre os conceitos básicos de Matemática Financeira. Isso ficou patenteado pelo uso incorreto de fórmulas, pela soma de taxas, por considerarem que o dinheiro, em uma data qualquer, equivale ao mesmo valor em uma data futura ou passada, dentre outros. 
Uma Proposta de Formação Continuada sobre Matemática Financeira para Professores de Matemática do Ensino Médio

Raphael Pereira dos Santos - Janaína Veiga - Ilydio Pereira de Sá

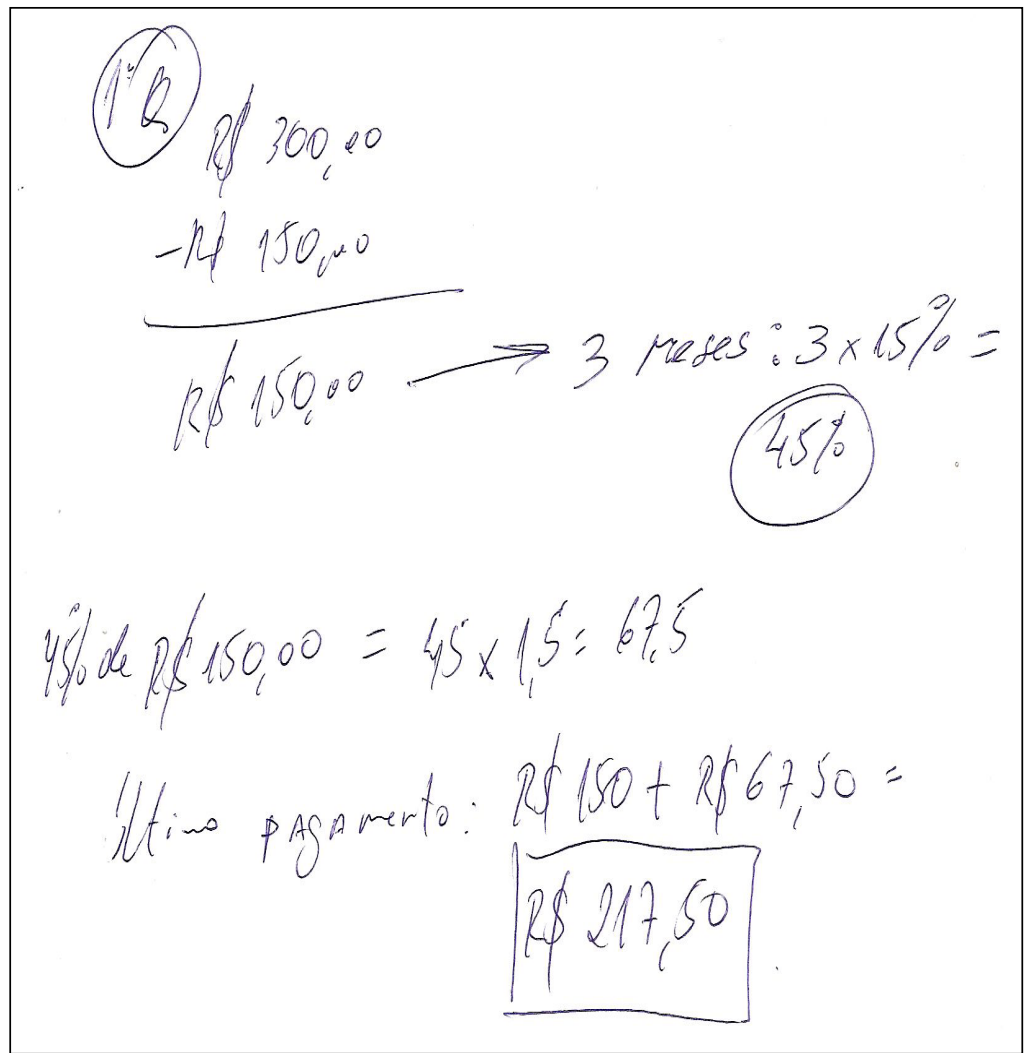

Figura 3. Solução de um professor participante para a questão 1 do teste diagnóstico.

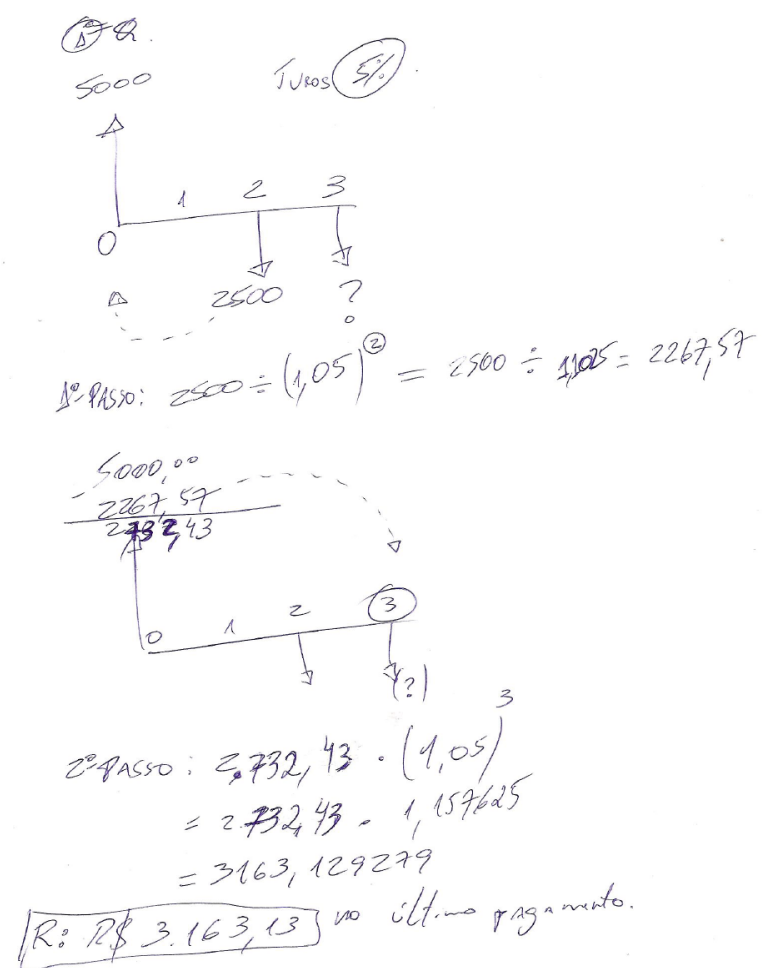

Figura 4. Solução de um professor participante para a questão 1 do teste pós-curso. 
Para corroborar o fato, apresentaremos as resoluções de um dos professores no teste diagnóstico (Figura 1) e no teste pós-curso (Figura 2), referentes à Questão 1, na qual constatamos $65 \%$ de erros no teste diagnóstico e $15 \%$ no teste pós-curso.

Percebe-se, claramente, a evolução desse professor no que se refere aos conteúdos de Matemática Financeira. Enquanto no teste diagnóstico ele ignorou que taxas e parcelas em datas distintas não podem ser somadas ou diminuídas (errando a questão), no teste pós-curso ele respeitou o valor do dinheiro no tempo, admitindo que as parcelas não têm o mesmo valor quando jogadas para um único período, acertando, a questão.

\title{
Considerações Finais
}

Os alunos, de fato, ao concluírem o ensino médio, devem estar preparados para entender e tomar decisões quanto às questões relacionadas a transações comerciais e financeiras presentes no cotidiano. Desde o início desta pesquisa, acreditamos que assuntos fundamentais do ensino médio, em particular a Matemática Financeira, contribuem para a formação cidadã do aluno. É seu direito ter acesso a uma formação digna no ensino médio. A Constituição de 1988 (Brasil, 1988) garante a todos os cidadãos o direito à educação, que é dever do Estado e da família, a qual deve visar o desenvolvimento da pessoa e seu preparo para o exercício da cidadania.

De acordo com D'Ambrosio (2001, p. 46), na condição de educadores temos uma grande missão para a preparação do futuro. $\mathrm{O}$ educador matemático deve fazer da matemática algo vivo, com situações reais no tempo e no espaço e, por meio da crítica, questionar o aqui e o agora.

\begin{abstract}
A matemática se impôs com forte presença em todas as áreas de conhecimento e em todas as ações do mundo moderno. Sua presença no futuro será certamente intensificada, mas não na forma praticada hoje. Será, sem dúvida, parte integrante dos instrumentos comunicativos, analíticos e materiais. A aquisição dinâmica da matemática integrada nos saberes e fazeres do futuro depende de oferecer aos alunos experiências enriquecedoras. Cabe ao professor do futuro idealizador, organizar e facilitar essas experiências. Mas, para isso, o professor deverá ser preparado com outra dinâmica.
\end{abstract}

Desde a Constituição Federal de 1988 (Artigo 206), a valorização dos profissionais da educação se apresenta como um princípio constitucional. A Emenda Constitucional n. ${ }^{0}$ 53/2006 alterou sua redação original, com alguns acréscimos no que se refere à valorização dos profissionais da educação pública, evidenciando a necessidade e urgência dessa valorização. A formação dos profissionais da educação, tanto a inicial como a continuada, deve ser examinada de forma contextualizada na sociedade brasileira e no cenário internacional.

A preocupação com a qualidade dos cursos de formação de profissionais da educação deve ser constante e seus currículos precisam dar a esses profissionais uma sólida formação teórica nos conteúdos específicos a serem ministrados na educação básica. Porém, muitas vezes nos deparamos com carências nessa formação inicial, as quais poderão ser supridas 
por meio de cursos de formação continuada e capacitação, utilizando, como apoio a esse processo, as inovações tecnológicas, de modo a tornar esse profissional capacitado para a sala de aula.

O professor precisa estar preparado para lecionar os conteúdos de forma contextualizada e a Matemática Financeira, sendo um fator de contextualização de conteúdos, torna-se fundamental ao cidadão-aluno na aquisição de conhecimentos para o exercício de sua cidadania. Como um aluno, na sociedade em que vive, pode discutir questões políticas, econômicas, ambientais sem esse suporte da Matemática?

Segundo Skovsmose (2001), a educação matemática deve ser desenvolvida como suporte da democracia. Dessa forma, ambos "professor e aluno" têm papel decisivo no processo educacional. Ele afirma que a educação deve ser constituída por problemas, com situações fora da sala de aula, resultando em uma formação crítica do cidadão para as práticas do cotidiano.

No “Guia de Livros Didáticos: PNLD 2010” (Brasil, 2009, p. 34), no item "Construção da cidadania", consta:

Contribuir para o desenvolvimento da ética necessária ao convívio social e à construção da cidadania, no livro didático de Matemática significa:

. Estimular o convívio social e a tolerância, abordando a diversidade da experiência humana com respeito e interesse;

. Promover o desenvolvimento da autonomia de pensamento, do pensamento crítico e da capacidade de argumentar;

- Utilizar conceitos e procedimentos matemáticos para promover a conscientização sobre problemas sociais.

No decorrer do curso de formação continuada, percebemos a preocupação dos professores em ensinar Matemática para uma formação cidadã do aluno e fazer dela um fator de inclusão na sociedade, sendo a Matemática Financeira um assunto fundamental para qualquer aluno/cidadão, além de presente no nosso cotidiano.

Os professores envolvidos ressaltaram a importância de cursos dessa natureza para o aperfeiçoamento dos profissionais que atuam em sala de aula, objetivando melhor domínio dos conteúdos e aquisição de novas estratégias para auxiliar no processo ensinoaprendizagem de Matemática. Há lacunas a serem preenchidas, seja devido a uma formação universitária deficiente, seja por falta de cursos de atualização e/ou especialização.

Os resultados do curso foram positivos como pudemos observar no teste aplicado na décima sessão, confirmando as hipóteses que tínhamos para esta pesquisa.

O estudo em questão foi de extrema importância em minha formação profissional. Constatei que um curso de formação continuada pode ajudar professores a rever conceitos e a desenvolver habilidades e estratégias próprias que favoreçam os alunos no processo ensino-aprendizagem da Matemática, com reflexões sobre a prática diária. 


\section{Notas}

1 O Projeto Fundão, que atua desde 1984, reúne grupos de professores e alunos de Licenciatura da UFRJ, que produzem pesquisas e materiais instrucionais e bibliográficos para orientação de profissionais e estudantes da área. O objetivo é complementar a formação dos alunos e proporcionar o acesso de professores do estado do Rio de Janeiro a pesquisas em Educação Matemática e de Ensino de Ciências. Disponível em: <http://www.jornaldaciencia.org.br/ Detalhe.jsp?id=47000>. Acesso em: 22 set. 2010.

2 Literacia matemática: capacidade de processar informação escrita e falada (D'Ambrosio, 2001, p. 66).

3 Numeracia social: competência que diz respeito ao uso de noções matemáticas relativamente pouco sofistic

\section{Referências}

Brasil (1988). Constituição da República Federativa do Brasil. Diário Oficial [da] União, Brasília, DF, 05 out. 1988. Disponível em: <http://www.planalto.gov.br/ccivil_03/ Constituicao/Constitui\%C3\%A7ao.htm>. Acesso em: 30 jan. 2010.

BRASIL (1996). Ministério da Educação. Lei n. ${ }^{\circ}$ 9.394, de 20 de dezembro de 1996. Estabelece as diretrizes e bases da educação nacional. Disponível em: <http://www. planalto.gov.br/ccivil_03/Leis/L9394.htm>.Acesso em: 30 jan. 2010.

Brasil (1998). Secretaria da Educação Fundamental. Parâmetros curriculares nacionais: matemática. Brasília: MEC/ SEF. Disponível em <http://www.mec.gov.br/sef/pcn5a8. shtm, 1998>.

Brasil (1999). Ministério da Educação. Secretaria de Educação Média e Tecnológica. Parâmetros curriculares nacionais: ensino médio. Brasília: Ministério da Educação.

Brasil (2009). Ministério da Educação. Guia de livros didáticos: PNLD 2010: alfabetização matemática e matemática. Brasília: Ministério da Educação, Secretaria de Educação Básica. 264 p.

D'Ambrosio (2001). Etnomatemática: elo entre as tradições e a modernidade. Belo Horizonte: Autêntica. 112 p. (Coleção Tendências em Educação Matemática).

D’Ambrosio (2004). Etnomatemática e educação. In: KNIJNIK, G.; WANDERER, F.; OLIVEIRA, C.J. (Org.). Etnomatemática, currículo e formação de professores. Santa Cruz do Sul: Ed. UNISC. pp. 39-52.

Domite, M. do C.S. (2002). Da compreensão sobre formação de professores e professoras numa perspectiva etnomatemática. In: KNIJNIK, G.; WANDERER, F.; OLIVEIRA, C.J. (Orgs.). Etnomatemática, currículo e formação de professores. Santa Cruz do Sul: Ed UNISC. pp. 419-431.

Fonseca, M. da C.F.R. (2005). O sentido matemático do letramento nas práticas sociais. Presença Pedagógica, Belo Horizonte, pp. 5-19, jul./ago.

Freire, P. (1992). Pedagogia da esperança: um reencontro com a pedagogia do oprimido. Rio de Janeiro: Paz e Terra.

Freire, P. (1996). Pedagogia da autonomia: saberes necessários à prática educativa. 36. ${ }^{\text {a }}$ ed. Rio de Janeiro: Paz e Terra. (Coleção Saberes). 
IBGE (2009). Estimativas das populações residentes. Disponível em: http://www.ibge.gov. br/home/estatistica/populacao/estimativa2009/POP2009_DOU. pdf. Acesso em: 22 de junho de 2012.

Marconi, M.A.; Lakatos, E.M. (2007). Fundamentos de metodologia científica. 6. ed. São Paulo: Atlas.

Minayo, M.C. de S. (Org.). (1994). Pesquisa social: teoria, método e criatividade. 18. ed. Petrópolis: Vozes. (Coleção Temas Sociais).

Pais, A.; Geraldo, H.; Lima, V. (2003). Educação matemática crítica e etnomatemática: conflitos econvergências. In: CONFERÊNCIAINTERAMERICANADEEDUCAÇÃO MATEMÁTICA, Blumenau, 2003. Anais... Blumenau: Universidade Regional de Blumenau e Comitê Interamericano de Educação Matemática. Disponível em: <http:// www.educ.fc.ul.pt/docentes/jfmatos/mestrados/fcul/aem/aem_ese/diversos_2003>.

Passos, C.M. dos. (2007). Possíveis articulações entre educação matemática crítica e etnomatemática. In: ARAÚJO, J. de L. (Org.). Educação matemática crítica: reflexões e diálogos. Belo Horizonte: Argumentum. pp. 83-96.

Skovsmose, O. (2000). Cenários para investigação. Bolema, v. 13, n. 14, p. 66-91.

Skovsmose, O. (2001). Educação matemática crítica: a questão da democracia. Campinas: Papirus. (Coleção Perspectivas em Educação Matemática).

Thiollent, M. (2000). Metodologia da pesquisa-ação. 10. ${ }^{a}$ ed. São Paulo: Cortez: Autores Associados. (Coleção Temas Básicos da Pesquisa-Ação). 